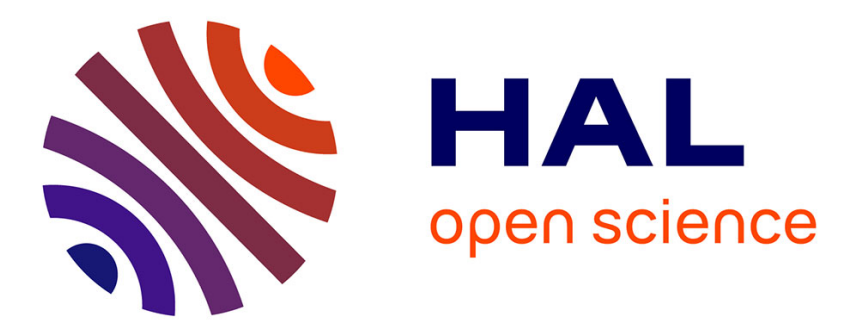

\title{
Preparation of microbridges and small area tunnel junctions
}

\author{
B. Kofoed, B.U. Jensen, K. Saermark
}

\section{To cite this version:}

B. Kofoed, B.U. Jensen, K. Saermark. Preparation of microbridges and small area tunnel junctions. Revue de Physique Appliquée, 1974, 9 (1), pp.191-194. 10.1051/rphysap:0197400901019100 . jpa00243736

\section{HAL Id: jpa-00243736 https://hal.science/jpa-00243736}

Submitted on 1 Jan 1974

HAL is a multi-disciplinary open access archive for the deposit and dissemination of scientific research documents, whether they are published or not. The documents may come from teaching and research institutions in France or abroad, or from public or private research centers.
L'archive ouverte pluridisciplinaire HAL, est destinée au dépôt et à la diffusion de documents scientifiques de niveau recherche, publiés ou non, émanant des établissements d'enseignement et de recherche français ou étrangers, des laboratoires publics ou privés. 


\title{
PREPARATION OF MICROBRIDGES AND SMALL AREA TUNNEL JUNCTIONS
}

\author{
B. KOFOED, B. U. JENSEN and K. SAERMARK
}

Physics Laboratory I, The Technical University of Denmark, DK-2800 Lyngby, Denmark

\begin{abstract}
Résumé. - Nous décrivons une technique d'évaporation pour préparer des microponts en couche mince, de largeur inférieure à $1 \mu$ et des jonctions tunnel de dimensions inférieures à $1 \mu \times 20 \mu$. On donne quelques exemples de caractéristiques $I-V$, montrant l'influence d'une onde hyperfréquence.
\end{abstract}

\footnotetext{
Abstract. - An evaporation technique for preparation of thin-film weak links with a width smaller than $1 \mu \mathrm{m}$ and tunnel junctions with an area smaller than $1 \mu \mathrm{m} \times 20 \mu \mathrm{m}$ is described. Some examples of $I-V$ characteristics and the influence of microwaves on the characteristics are given.
}

Various techniques for preparation of thin-film weak links have been discussed in the literature [1]. Often the thin-film is evaporated onto the substrate utilizing a suitable masking [2], at times including a photo-etching [3] or a razor-blade cutting procedure [4]. In the latter case the dimensions of the bridge region are of the order of $0.5 \mu \mathrm{m}$ wide by $0.2 \mu \mathrm{m}$ long, and typical resistances below $T_{\mathrm{c}}$ are reported to be of the order of $0.5 \Omega$.

In the present note we report on an evaporation technique for preparation of thin-film weak links. The new feature consists of a specially designed mask the main elements of which are two precision hemispheres - or nearly hemi-spheres - mounted as discussed below. The width of the thin-film weak links is normally below $1 \mu \mathrm{m}$ and typical resistances obtained below $T_{\mathrm{c}}$ are $70 \Omega$. It is, further, possible to use the device for making small area tunnel junctions of the crossed film type. Typically areas of the order of $1 \mu \mathrm{m} \times 20 \mu \mathrm{m}$ are obtained.

The technique has turned out to be very reliable in the sense that nearly all weak links and tunnel junctions produced in this way do show the usual $I-V$ characteristics and with a given setting of the mask one obtains very nearly identical weak links and tunnel junctions. Examples of $I-V$ characteristics obtained with and without incoming microwaves will be presented below.

In principle the weak links are prepared by evaporating a metal film (marked $F$ ) between two hemispheres (marked S) placed on a glass substrate (marked G), as shown in figure 1 , where the evaporation is thought to take place from above. For preparation of a tunnel junction the substrate is removed from

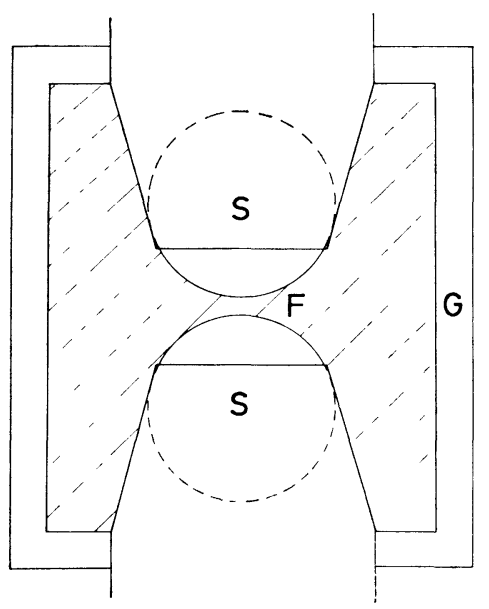

Fig. 1. - The principle for evaporation of a weak link. The hemi-spheres are marked $\mathrm{S}$, the substrate is marked $\mathrm{G}$ and the metal film is marked $\mathrm{F}$.

the hemi-spheres and a cross-strip is evaporated after and oxidation process.

In the following a short description of the mechanical arrangement allowing one to mount the two hemi-spheres on the glass substrate and to separate them less than $1 \mu \mathrm{m}$ apart is given.

The hemi-spheres are made out of two precision spheres (chromium steel) for ball-bearings with diameter $390 \pm 0.1 \mu \mathrm{m}$ (also spheres with a diameter of $0.35 \mathrm{~mm}$ have been used). The spheres are ground and polished to hemi-spheres with an equatorial diameter about $0.35 \mathrm{~mm}$ and a height about $0.15 \mathrm{~mm}$. The last grinding and polishing is performed with diamond powder in order to secure a plane bottom 
face and a sharp periphery of the hemi-spheres. The hemi-spheres are placed on a plane under the holes at the end of the bronzesprings (numbered 8 in Fig. 2) and subsequently glued to the springs.
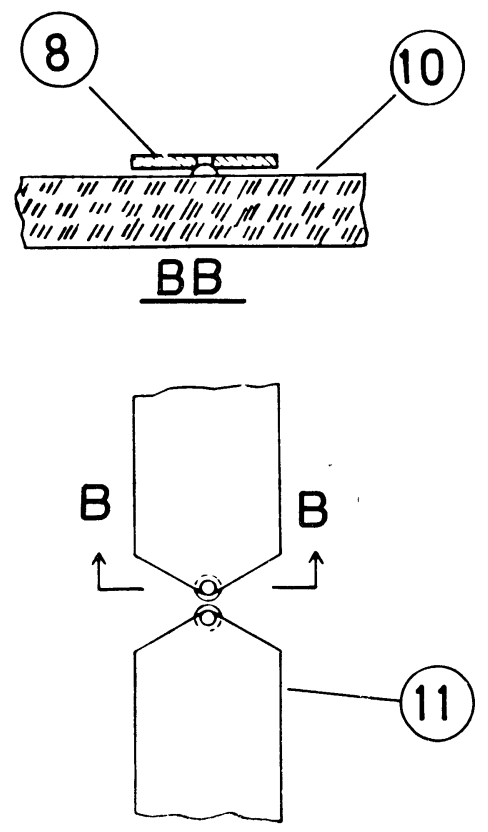

FIG. 2. - The principle for mounting the hemi-spheres on the bronzesprings. The bronzespring is numbered 8 .

Figure 3 shows the drawing of the mechanical arrangement by means of which it is possible to adjust the distance between the spheres. The two bronzesprings with the spheres are attached to each of the prismatic guides (numbered 6). The prismatic guides are kept in place by the tumbler springs (numbered 7), and they can be moved by means of the screws (numbered 5). Using the screws it is by inspection in a microscope possible to place the two hemi-spheres less than $1 \mu \mathrm{m}$ apart on a glass substrate. The glass substrate is from below pressed against the bronzeprings and the evaporation takes place from above (in Fig. 3) through the guard plate (numbered 4).

After the evaporation the substrate is removed from the mechanical arrangement, and the weak link is ready for use. A picture of a weak link made in this way is shown in the insert in figure 4. In fabrication of a tunnel junction a cross-strip is evaporated on the top of the weak link after oxidation, and a junction with area smaller than $20 \times 10^{-6} \mathrm{~mm}^{2}$ is obtained.

In the following we show some examples of $I-V$ characteristics for weak links and tunnel junctions produced in this way.

Figure 4 shows $I-V$ characteristics for an In thinfilm weak link with and without incidence of microwaves. The microwave frequencies are $63 \mathrm{GHz}$ and $302 \mathrm{GHz}$, and the Josephson steps corresponding to these frequencies are easily observed at low reduced temperature $(t=0,466)$. This indicates a very good microwave coupling to the weak link.
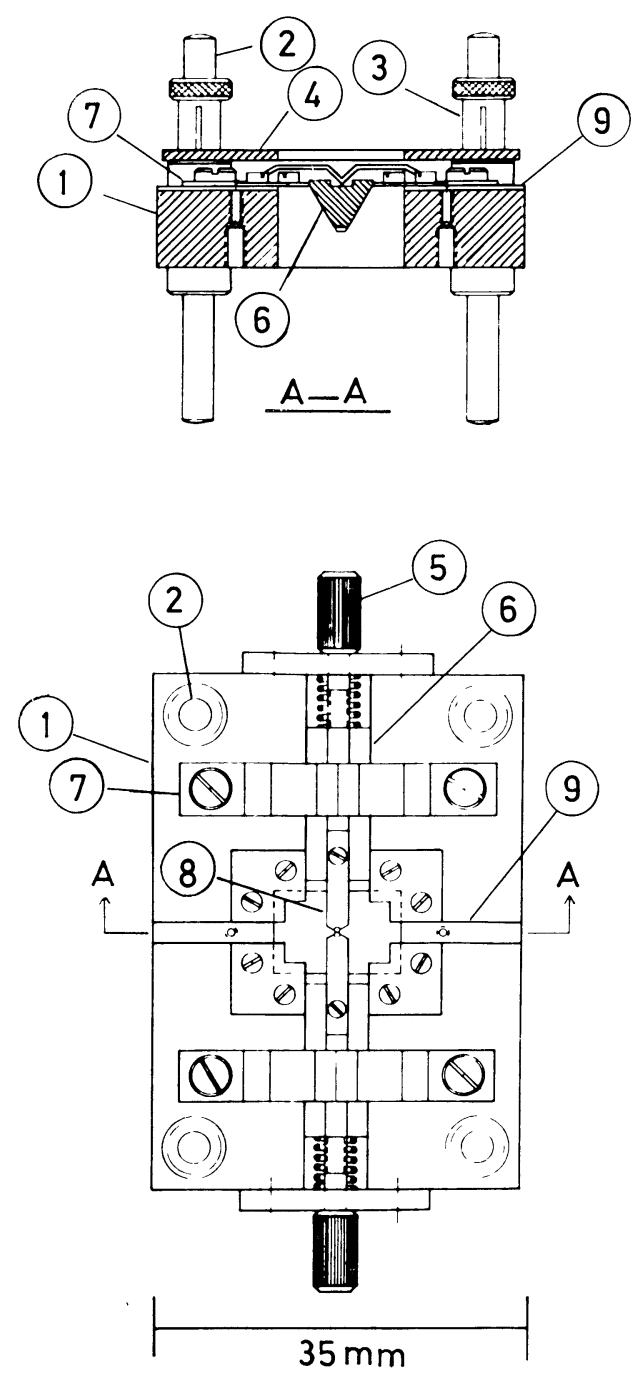

FIG. 3. - The mechanical arrangement for adjusting the distance between the spheres.

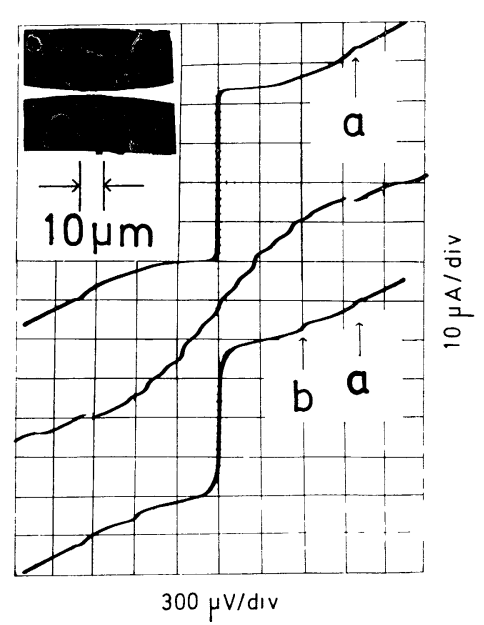

FIG. 4. - I-V characteristic for an In weak link at $1.58 \mathrm{~K}$. Top curve : without applied microwaves; middle curve : exposed to $63 \mathrm{GHz}$ microwaves; bottom curve : exposed to $302 \mathrm{GHz}$ microwaves. Insert : a photo of a typical weak link. 
The bump on the curves, marked by the arrow a, occurs at a voltage which corresponds well with the energy gap value $2 \Delta / \mathrm{e}=1.02 \mathrm{mV}$ for $\mathrm{In}$ at this temperature. Figure 5 shows the dynamic resistance as function of the bias for the same weak link with applied $63 \mathrm{GHz}$ microwaves. The insert shows the temperature variation of the bump indicated by the arrow a in figure 4 and for a similar bump on a $\mathrm{Sn}$ $I-V$ characteristic. The temperature variation of the bumps is compared with the BCS-curve for the temperature variation of the energy gap.

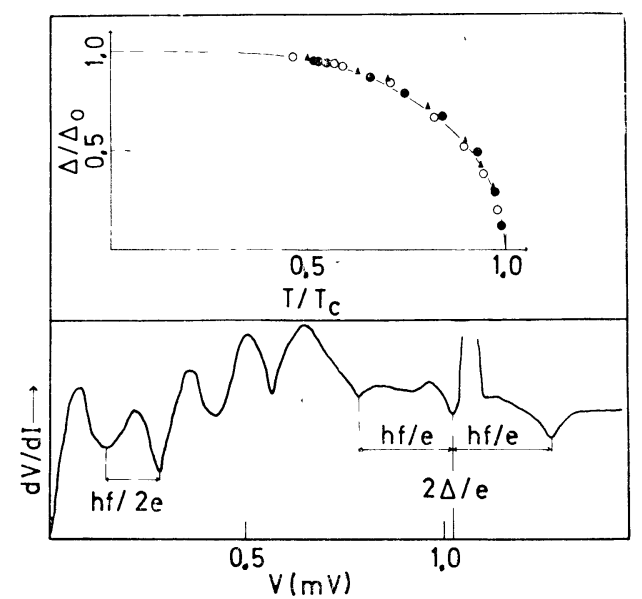

Fig. 5. - Dynamic resistance as function of the bias for an In weak link at $1.58 \mathrm{~K}$ exposed to $63 \mathrm{GHz}$ microwaves. The insert shows the measured energy gap versus the reduced temperature compared with the BCS-theory for two In weak links (circles) and one Sn weak link (triangles).

In figure 5 one notes (besides the Josephson step structure) an additional structure on either side of the gap. The separation of this structure from the gap is $h f / \mathrm{e}$. On the basis of the power dependence of this additional structure we conclude that the structure is caused by microwave assisted tunneling [5].

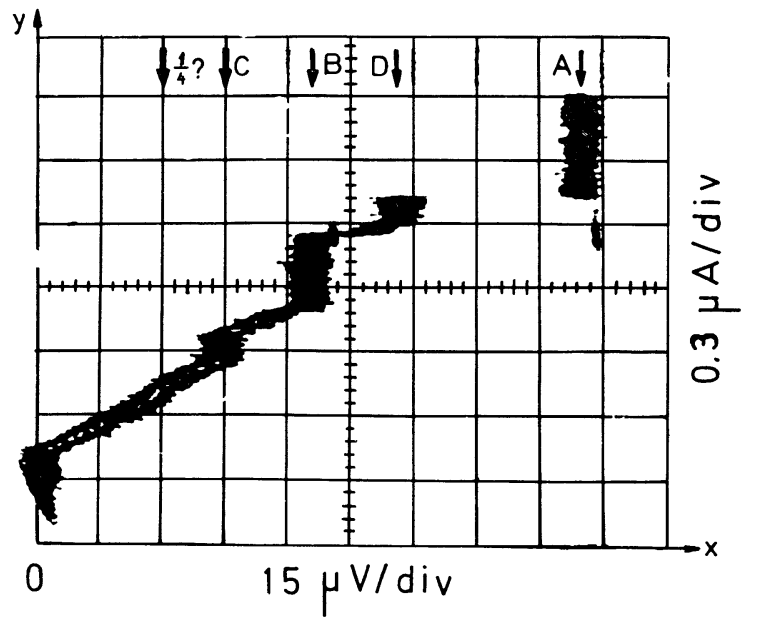

FIG. 6. - I- $V$ characteristic for a $\mathrm{Sn}$ weak link exposed to $70 \mathrm{GHz}$ microwaves. Subharmonics of the first Josephson step (marked A), corresponding to $\frac{1}{2}, \frac{1}{3}$ and $\frac{2}{3}$ (marked respectively $\mathbf{B}$, $\mathrm{C}$ and D) of the first Josephson step are seen.
Subharmonics or more correctly subharmonics of the Josephson steps have also been observed in thinfilm weak links. Figure 6 shows the $I-V$ characteristic for a Sn weak link with applied $70 \mathrm{GHz}$. Subharmonic steps are seen corresponding to $\frac{1}{2}, \frac{1}{3}$, possible $\frac{1}{4}$ and $\frac{2}{3}$ of the first microwave induced Josephson step indicated by the arrow $\mathrm{A}$. The $I-V$ characteristic for the same weak link with $70 \mathrm{GHz}$ and $10 \mathrm{GHz}$ radiation applied simultaneously is shown in figure 7 . Steps corresponding to $70 \pm 10 \mathrm{GHz}$ and to $35 \pm 5 \mathrm{GHz}$ are seen, which also should be expected.

As examples of characteristics obtained with the small area cross-strip tunnel junctions figure 8 shows the $\mathrm{d} V / \mathrm{d} I, V$ characteristics for a $\mathrm{Sn}-\mathrm{O}-\mathrm{Sn}$ junction with applied $3.9 \mathrm{GHz}$ microwaves. One notes that at high power levels - large $\alpha$-values, $\alpha=\mathrm{e} V_{\text {rf }} / h f-$

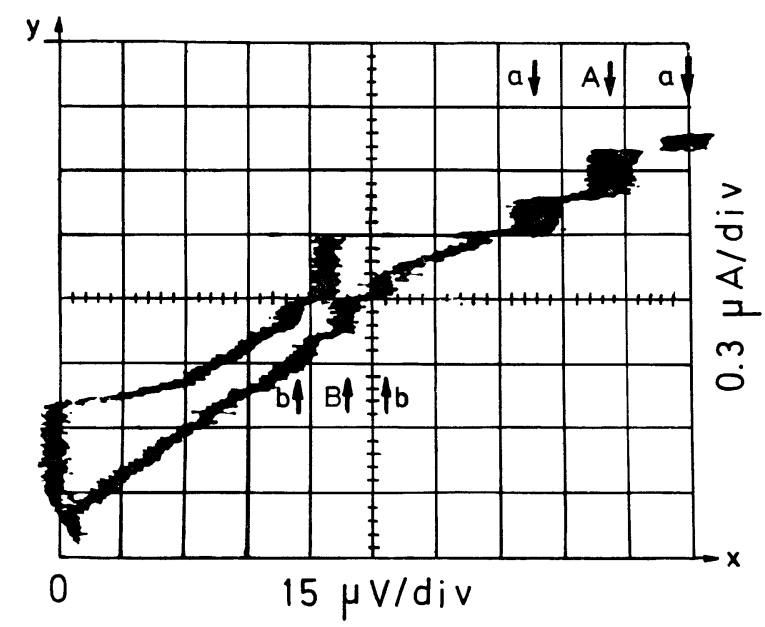

FIG. 7. - I- $V$ characteristic for the same $\mathrm{Sn}$ weak link as shown in figure 6 exposed simultaneously to $70 \mathrm{GHz}$ and $10 \mathrm{GHz}$ microwaves. Steps corresponding to $70 \pm 10 \mathrm{GHz}$ are marked a. Steps corresponding to $35 \pm 5 \mathrm{GHz}$ are marked $\mathrm{b}$.

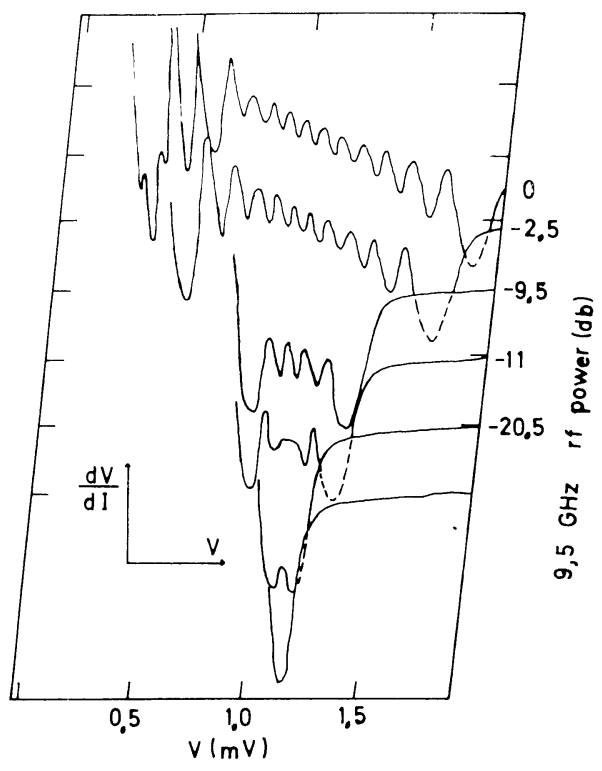

FIG. 8. $-\mathrm{d} V / \mathrm{d} I, V$ characteristics for a Sn-O-Sn tunnel junction exposed to $3.9 \mathrm{GHz}$ microwaves. 
oscillations in the characteristics turn up. These oscillations are in full agreement with the Tien-Gordon expression for the microwave assisted tunneling. This indicates that the detection even at the rather low frequency $3.9 \mathrm{GHz}$ is not purely classical (cf. ref. [6]). In these small area junctions there is essentially no spatial variation of the microwave induced field in the junction. Figure 9 shows $\mathrm{d} V / \mathrm{d} I, V$-characteristics

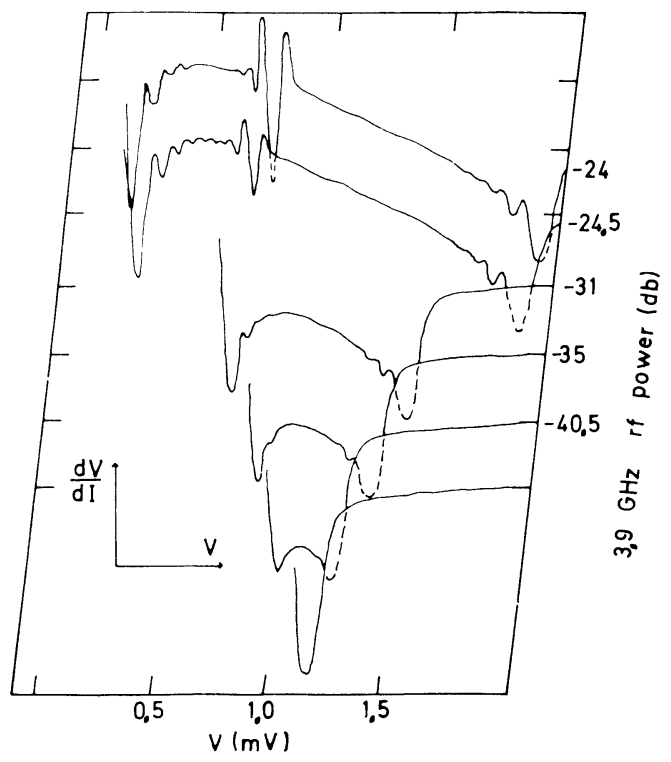

Fig. 9. $-\mathrm{d} V / \mathrm{d} I, V$ characteristics for the same Sn-O-Sn tunnel junction as shown in figure 8 exposed to $9.5 \mathrm{GHz}$ microwaves. for the same junction with applied $9.5 \mathrm{GHz}$. Again for large $\alpha$-values oscillations in the characteristics are observed.

As a last example figure 10 shows the $I-V$ characteristic for a Sn-O-Sn tunnel junction where subharmonics of the energy gap structure are observed. With applied microwaves the satellite structure associated with the energy gap structure appears. This subject is dealt with in the paper by $\mathrm{O}$. H. Soerensen et al.

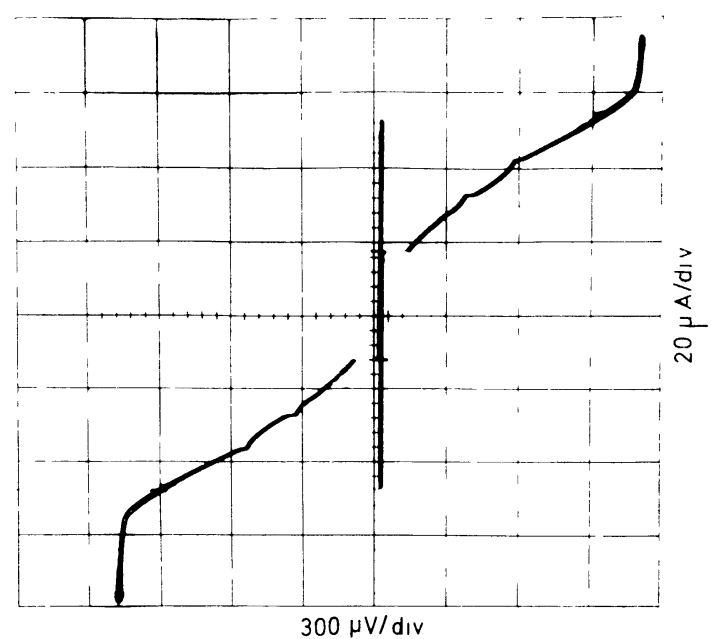

FIG. 10. - I-V characteristic for a Sn-O-Sn tunnel junction with distinct bumps belonging to the subharmonic energy gap structure.

\section{References}

[1] Solymar, L., Superconductive Tunneling and Applications (Chapman and Hall) 1972, 240-243.

[2] Dayem, A. H. and Wiegand, J. J., Phys. Rev. 155 (1967) 419.

[3] Seraphin, G. R. S., D. Phil. Thesis (Dept. of Engineering Science, Oxford University) 1970.
[4] Gregers-Hansen, P. E. et al., J. Low Temp. Phys. 7 (1972) 99.

[5] Kofoed, B. and Saermark, K., Phys. Rev. Lett. 31 (1973) 1124.

[6] Hamilton, C. A. and Shapiro, S., Phys. Rev. B2 (1970) 4494. 